www.jmscr.igmpublication.org

Impact Factor 5.84

Index Copernicus Value: 71.58

ISSN (e)-2347-176x ISSN (p) 2455-0450

crossref DOI: _https://dx.doi.org/10.18535/jmscr/v5i10.12

Journal Of Medical Science And Clinical Research

IGM Publication

An official Publication of IGM Publication

\title{
Immediate Effectiveness of Dorn Therapy in chronic Low Back Pain: A Case Report
}

\author{
Authors \\ Girija Murugan', Subhash M Khatri \\ ${ }^{1}$ Masters Student, Dr. APJ Abdul Kalam College of Physiotherapy, Loni, Ahmednagar, Maharashtra India- \\ 413736 \\ Email: girijamurugan2106@gmail.com \\ ${ }^{2}$ Principal, Dr. APJ Abdul Kalam College of Physiotherapy, Loni, Ahmednagar, Maharashtra, India-43 7376
}

\begin{abstract}
Introduction: Low back pain is a common symptom among working age population. Farming is the major occupation in many developing countries. Most of the farmers lack ergonomic knowledge which predisposes them into musculoskeletal disorders, majorly low back pain. Women farmers who learnt to live with pain are at higher risk.

Case Description: A 38 yr old female farm worker with chronic intermittent low back pain for past 2 years, had undergone physiotherapy treatment and medications repeatedly for the same. And with the recent recurrence of pain, she visited the Orthopaedic outpatient department and she was advised for physiotherapy. Her functional activities were disturbed.

Procedure: A lesser explored technique of Dorn therapy was adopted to relieve pain and restore mobility of lumbar spine.

Result: Prior to the treatment, scores of NRS for forward flexion was 8/10and for floor sitting was 9/10, the scores of Pressure Pain Threshold at L4 spinous process was $4 \mathrm{lbs}$ and at L5 spinous process was $6 \mathrm{lbs}$ and the measurement for finger to floor test was $35 \mathrm{~cm}$. After the application of Dorn therapy, scores of NRS for forward flexion was 3/10 and for floor sitting was 5/10, the scores of Pressure Pain Threshold at L4 spinous process was $7 \mathrm{lbs}$, and at L5 spinous process was $8 \mathrm{lbs}$ and the measurement for finger to floor test was $23 \mathrm{~cm}$.

Purpose: This study describes the immediate effectiveness of Dorn therapy in a farmer with chronic low back pain and will help understand the clinical importance of the less spoken Dorn therapy. And this report will emphasize on the application of this therapy in clinical settings to achieve immediate results.

Limitations and Recommendations: Since this a case study, the results cannot be generalised in a larger sample size. Further research is needed to explore selection of Dorn therapy and its effectiveness could be studied in long term to provide a better understanding of the treatment parameters.

Keywords: Chronic Low Back Pain, Manual therapy, Dorn therapy, Farmers.
\end{abstract}

Evolution of human is perfect, but has come with certain compromise - that is pain, most commonly low back pain. Low back pain prevalence increases linearly from the third decade of life,till 60 years of age, then gradually declines and more prevalent in women ${ }^{[1,2]}$. 
Farming accounts about half the world's entire labour force. In many countries, farming is recognized as one of the most unsafe industries. Farming activities has the highest risk of workrelated musculoskeletal disorders than other occupational activities ${ }^{[3]}$. It is a unique but an unorganised sector. Farmers has to adapt to various uncertainties like environmental changes, physical stress, psychosocial problems, type of work with respect to the cropetc. ${ }^{[4]}$

There is no limit to women's effort in rural farms. Women comprise about 43 percent of the agricultural labour force globally and in developing countries ${ }^{[5]}$. The daily schedule of a farming women is energy demanding to take care of the farm animals in addition to household and farming activities ${ }^{[6]}$. Indian women continue to use the same traditional tools for their work. Long hours of work, continuousattention, variety in works like paddy transplanting, weeding, harvesting, sowing, and threshing and attainment ofawkward body postures like leaning, kneeling, crawling, prolonged bending, repetitive twisting, lifting and carrying heavy loadscan result in physical stress and traumatic injuries ${ }^{[4,7]}$. Most of the farmers lack awareness of the ergonomic reflection of their work activities and occupational safety which predisposes them to pain and discomfort ${ }^{[8]}$. "Having learned to live with pain" makes women more vulnerable to higher risk ${ }^{[9]}$.

According to anepidemiological survey done on agricultural workers from Kanpur- Rural India, sample workers reported musculoskeletal symptoms to their work, out of which a whopping 60 per cent reported with low back pain ${ }^{[7]}$.

Low back pain also affects the quality of life (QOL) of not only the women themselves, but their families as well and also reduces productivity ${ }^{[6]}$. Poor quality of life suggests the need of coping strategies, regular health checkups, health education program and a proper working time table ${ }^{[9]}$.

This case report describes the successful immediate effectiveness of Dorn therapy in a ladyfarm worker with chronic intermittent low back pain, it will probablyestablish an evidence of this manual therapy technique. This report will also help the therapist to select a technique which requires active participation from the patient, making him/heran integral component of the treatment session. The ultimate selection of this technique was to provide immediate pain relief and reduce disability caused by low back pain.

\section{Description of case:}

This case report followed a farmer with chronic intermittent low back pain which prolonged for two years. The outcome measures included Numerical rating scale for pain, for floor sitting and forward flexion, Pressure pain threshold at L4 and L5 spinous process and the finger to floor test measurement, are being presented.

History: Mrs. S, a 38 yearoldlady farm worker, hadconsiderable low back pain for 2years. She visited Orthopedic department with the recent recurrence of pain, for which she was advised to take NSAIDs and for physiotherapy treatment.

Examination: Grade 2 local tenderness at L4 and L5 spinous process. She had bilateral Hamstring, Tendo Achilles and Iliopsoas tightness. FABER Patric test was bilaterally positive.

Investigation: Lumbar spine $X$ ray in anteroposterior and lateral views were taken in standing. It revealed a maintained lumbar lordosis and narrowing of the intervertebral foraminal space between L4-L5 and L5-S1 vertebraeand osteophyte formation.

Consent: After examination, the therapist explained the findings, about the procedure and the requirement of the procedure. And asked for her consent in written.

Pre therapy scores: Scores of NRS for forward flexion was $8 / 10$ and for floor sitting was $9 / 10$ and, the scores of Pressure Pain Threshold at L4 spinous process was $4 \mathrm{lbs}$ and at L5 spinous process was $6 \mathrm{lbs}$ and themeasurement for finger to floor test was $35 \mathrm{~cm}$.

Patient position: Standing with arms along the sides and neck in neutral position. 
Procedure: Prior to the treatment, her co-operation was requested for and she was said to perform lumbar flexion and extension alternately and rhythmically. The therapist stood lateral to the patient facing her and stabilised the anterior aspect of the pelvis with the left hand and made a fist on the right hand. With the knuckles of the right hand applying a slight pressure to the spinous process of the lower lumbar vertebrae and maintaining the pressure, she was asked her to perform lumbar flexion and extension alternately 10 times each. Initially she had some discomfort to perform and gradually she got accustomed to the action to be performed. After a period of relaxation, the second set of 10 repetitions each, was given while applying the pressure to the vertebrae. Again followed by the third set. A brief re- assessment was done between each set.

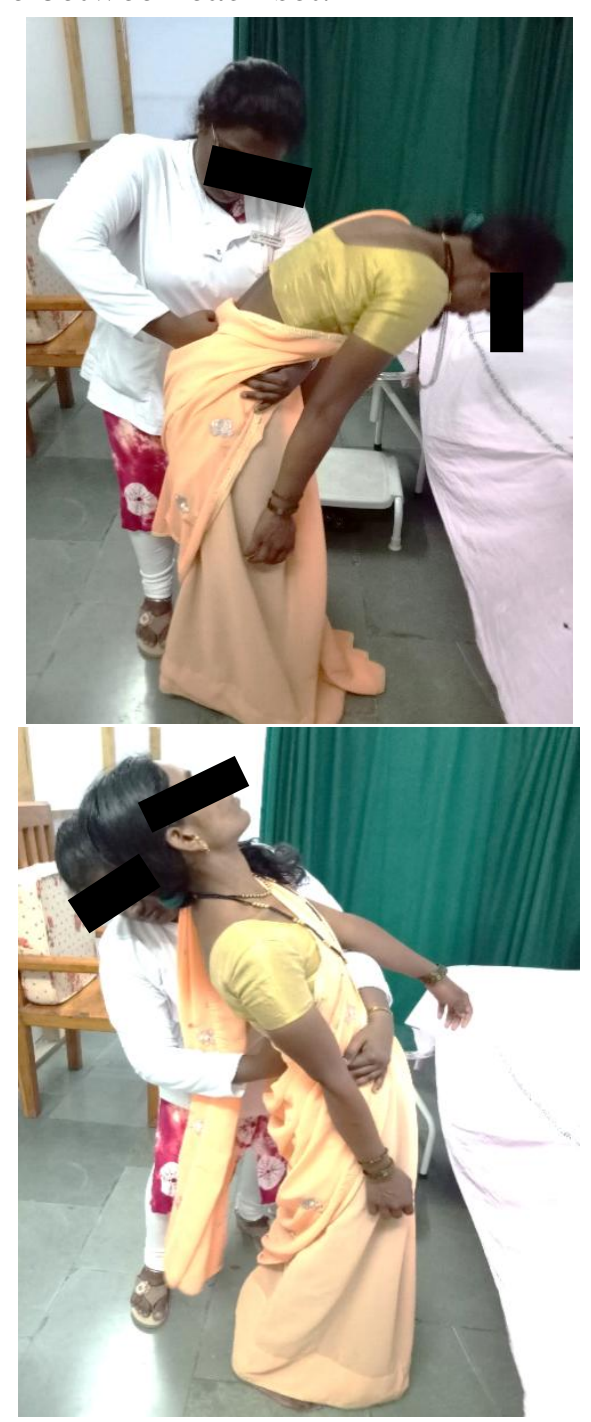

Fig.1 \& 2 Demonstrates the application of Dorn therapy to the patient
Post therapy scores: Scores of NRS for forward flexion was $3 / 10$, and for floor sitting was $5 / 10$, the scores of Pressure Pain Threshold at L4 spinous process was $7 \mathrm{lbs}$, and at L5 spinous process was $8 \mathrm{lbs}$ and themeasurement for finger to floor test was $23 \mathrm{~cm}$.

\section{Discussion}

To the best of our knowledge, this case report is different from previous studies, as this is probably the first attempt to demonstrate the application of Dorn therapy in chronic low back pain.

Mrs. S showed considerable benefit in terms of pain relief and spinal mobility. Although, we could not study the cause and effect relationship or exact effect and mechanism of action. It has been stated that Dorn therapy aims for the independence of the patient. Dorn therapy practitioners believe thatmovement is a fundamental element in the treatment, all corrections happen in dynamics, this movement stretch the muscles so they can't offer any resistance to the correction thus muscle tension is released as well as muscles length is maintained. Mechanical principles of counter pressure and leverage forces in combination with the active participation of the client provides muscle flexibility, and this form of correction is usually readily accepted by the body ${ }^{[10]}$.

This manual therapy technique with its immediate relief of pain, gave the female a psychological benefit as well. She developed a good adherence and compliance to the treatment. For a farmer like her, who stays far away from the hospital and who cannot turn upto the physiotherapy department regularly, this therapy followed by home exercises and ergonomic advices could be beneficial.

Dorn therapy is with almost no risk and requires very short treatment period in a session. The report findings suggest that Dorn therapy can be given to patients with chronic low back pain, unless noted with any serious illness, after getting the proper consent from the patient. 


\section{Conclusion}

Dorn therapy technique may be used as an adjunct to conventional physiotherapy for the immediate relief of chronic intermittent low back pain and stiffness due to lumbar spondylosis.

Limitations and Recommendations: Since this a case study, the results cannot be generalised in a larger sample size. Further research is needed to explore selection of Dorn therapy and its effectiveness could be studied in long term to provide a better understanding of the treatment parameters.

Conflicts of interests: None declared.

\section{References}

1. MeucciR, FassaA, MullerN, FariaX. Prevalence of chronic low back pain: Systematic review. Revista de saudepublica.2015; 49:1-10.

2. Atlas SJ and Deyo RA. Evaluating and Managing Acute Low Back Pain in the Primary Care Setting. Journal of General Internal Medicine. 2001; 16(2): 120-31.

3. Omran A, Reza G, Shamsedin AS, Yahya $\mathrm{R}$ and Pouria DS. Prevalence of Musculoskeletal Disorders Among Farmers in Eastern Azerbaijan, Iran. Indian Journal of Science and Technology. 2015; 8(28):1-6.

4. Murthy SR, Nikhade N. Prevalence of Musculoskeletal Disorders in Farmers of Ahmednagar District. International Journal of Innovative Research in Medical Science.2017; 2(3): 635-641.

5. The role of women in agriculture. Agricultural Development Economics Division. The Food and Agriculture Organization of the United Nations. [http://www.fao.org/docrep/013/am307e/a m307e00.pdf]

6. Ahdhi GS, Subramanian R, Saya GK, Yamuna TV. Prevalence of low back pain and its relation to quality of life and disability among women in rural area of Puducherry, India.Indian Journal of Pain. 2016;30(2)111-115.

7. Gupta G and Tarique. Prevalence of Musculoskeletal Disorders in Farmers of Kanpur-Rural, Journal of Community Medicine and Health Education. 2013; 3(7).

8. Susanto T, Purwandari R, Wuryaningsih E WPrevalence and associated factors of health problems among Indonesian farmers. Chinese Nursing Research. 2017;4(1) :31-37.

9. SutharN and Kaushik V. Musculoskeletal Problems among Agricultural Female Workers. Studies on Home and Community Science. 2013; 7(3): 145-149.

10. Thomas Zudrell. The Dorn Method. First edition. Philippines: Dream Time;2005.

\section{List of Abbreviations}

NRS: Numerical Rating Scale lbs: Pounds

NSAIDs: Non-steroidal anti- inflammatory drugs 